\title{
Penerapan COBIT-5 Domain DSS01 dan DSS05 Untuk Mengukur Kualitas Tata Kelola Sistem di KSPPS BMT Unit 068-Sampit
}

\author{
Angga Yogi Pratama, Muhammad Fajrin Anshari, Anisa Agustina Melani \\ Fakultas Ilmu Komputer, Sistem Informasi, Universitas Darwan Ali, Sampit, Indonesia \\ Email: ${ }^{2}$ anggaspt1818@gmail.com , ${ }^{2}$ mfajrin123456@gmail.com, ${ }^{3}$ anisamelani238@gmail.com
}

\begin{abstract}
Abstrak- Baitul Maal wa Tamwil (BMT) adalah suatu lembaga yang mendukung kegiatan ekonomi masyarakat kecil bawah dengan berlandaskan sistem ekonomi syariah islam. KSPPS BMT KUBE SEJAHTERA 068 Sampit dibentuk pada tanggal 12 Januari 2006 dengan badan Hukum Koperasi No. 07/Kep-BH/DK.PM/VIII/2006, dan merupakan Koperasi Simpan Pinjam dan Pembiayaan Syariah (KSPPS) yang telah memiliki pengalaman kisaran kurang lebih sepuluh tahun melayani dan bermitra dengan masyarakat. Pada KSPPS BMT-Sampit masih belum adanya sistem pengauditan untuk memonitor apakah teknologi yang ada sudah berjalan secara baik dan efisien, serta untuk memberikan penilaian tingkat kematangan teknologi sistem informasi maka dari itu penulis menggunakan framework Cobit 5 untuk sistem audit tersebut dengan berfokus pada 2 domain yang menjadi pilihan yaitu DSS01 (manage operation) dan DSS05 (manage security servis)berdasarkan hasil perhitungan yang sudah di lakukan maka tingkat kematangan teknologi informasi yang ada di KSPPS BMT-Sampit berada pada level 4 (Predictable proces) untuk DSS01, dan berdasarkan level 4 (Predictable proces) untuk DSS05.
\end{abstract}

Kata Kunci: BMT; TI; Dss01; Dss05; Cobit5

Abstract-Baitul Maal wa Tamwil (BMT) is an institution that supports the economic activities of low-income communities based on the Islamic sharia economic system. KSPPS BMT KUBE SEJAHTERA 068 Sampit was formed on January 12, 2006 with the legal entity Cooperative No. 07/Kep-BH/DK.PM/VIII/2006, and is a Sharia Savings and Loans Cooperative (KSPPS) which has approximately ten years of experience serving and partnering with the community. At KSPPS BMT-Sampit there is still no auditing system to monitor whether the existing technology is running well and efficiently, as well as to provide an assessment of the maturity level of information system technology, therefore the author uses the Cobit 5 framework for the audit system by focusing on 2 domains that the choices are DSS01 (manage operation) and DSS05 (manage security service) based on the results of calculations that have been done, the maturity level of information technology in KSPPS BMT-Sampit is at level 4 (Predictable processes) for DSS01, and based on level 4 (Predictable Processes) for DSS05.

Keywords: BMT; TI; Dss01; Dss05; Cobit5

\section{PENDAHULUAN}

Baitul Maal wa Tamwil (BMT) adalah suatu lembaga yang mendukung kegiatan ekonomi masyarakat kecil bawah dengan berlandaskan sistem ekonomi syariah islam. BMT mempunyai dasar hukum yaitu koperasi syariah[1]. KSPPS BMT KUBE SEJAHTERA 068 Sampit dibentuk pada tanggal 12 Januari 2006 dengan badan Hukum Koperasi No. 07/KepBH/DK.PM/VIII/2006, dan merupakan Koperasi Simpan Pinjam dan Pembiayaan Syariah (KSPPS) yang telah memiliki pengalaman kisaran kurang lebih sepuluh tahun melayani dan bermitra dengan masyarakat. KSPPS BMT KUBE SEJAHTERA 068 dibentuk dengan bertujuan untuk menjembatani keuangan masyarakat sampit di tingkat mikro, yang dijalankan dengan menggunakan sistem syariah dan dijalankan oleh manajemen yang profesional [2].

Dengan semakin berkembangnya teknologi informasi dan komputerisasi, banyak perusahaan yang telah menggunakan teknologi untuk memudahkan berbagai urusan didalam suatu perusahaan. Tidak terkecuali KSPPS BMT 068-Sampit salah satu instansi yang telah menggunakan teknologi informasi, pada KSPPS BMT 068-Sampit telah menerapakan teknologi informasi dalam melakukan proses pelayanan kepada nasabah-nya dengan menggunakan sistem IBS collect. namun ada beberapa permasalahan yang teridentifikasi yaitu masih belum adanya sistem pengauditan untuk memonitor apakah teknologi yang di gunakan sudah berjalan dengan baik dan efesien, serta untuk memberikan penilaian tingkat kematangan teknologi informasi.

Salah satu sistem audit tersebut yaitu Cobit5, merupakan framework yang telah menyajikan standar dalam framework domain yang berjalan. Cobit5 disini diterapkan untuk mengukur sebuah tingkat kapabilitas teknologi informasi dalam sebuah layanan sistem informasi pada KSPPS BMT-Sampit. Dan untuk mengetahui tingkat resiko keamanan informasi yang dapat diterima organisasi sesuai kebijakan keamanan. Dengan demikian domain yang digunakan dari Cobit5 untuk melakukan audit layanan sistem informasi dan untuk mempertahankan tingkat kemanan informasi pada penelitian ini yaitu domain Delivery, Service and Support (DSS) dan subdomain yang digunakan yaitu DSSO5 (Mengelola Keamanan Sistem) dan DSSO1 (Mengelola Operasi).

\subsection{Desain Penelitian}

\section{METODOLOGI PENELITIAN}

Dalam penelitian ini yang menjadi objek penelitian adalah KSPPS BMT KUBE SEJAHTERA 068 yang terletak di Jln. Kopi Simpang Delima 1 No.65 A, Sampit Kotawaringin Timur. Penelitian ini bermaksud melihat tingkat kualitas tata kelola sistem, yang dimana berfokus pada pengelolaan keamanan sistem dan pengelolaan proses sistem menggunakan COBIT-5. Adapun rancangan alur penelitiannya di proses dalam beberapa tahapan seperti berikut ini : 


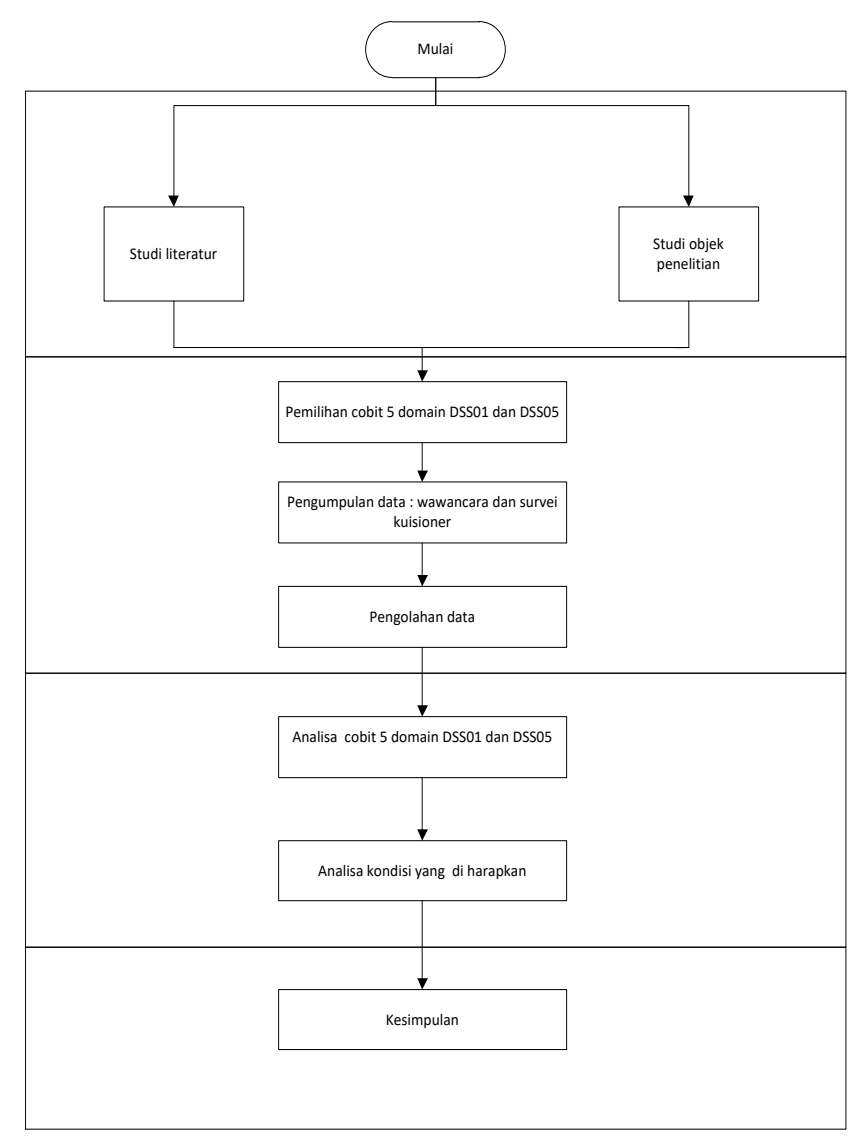

Gambar 1. Diagram Alur Penelitian

Tahapan-tahapan yang akan dilakukan dalam mengukur kualitas tata kelola sistem seperti pada gambar 1, sebagai berikut:

1. Studi literatur, dilakukan dengan menelaah referensi dari berbagai sumber pustaka seperti penelitian terdahulu, jurnal, dan artikel, serta menelaah proses sistem di perusahaan yang diteliti.

2. Studi objek penelitian, dilakukan dengan mengajukan quisioner dan sesi wawancara kepada responden atau pihak perusahaan.

3. Pemilihan COBIT, dilakukan berdasarkan studi pustaka dan juga studi objek penelitian dengan berfokus pada COBIT5 domain DSS01 dan DSS05.

4. Pengumpulan data, dilakukan dengan wawancara dan membuat kuisioner yang ditujukan kepada pihak organisasi terhadap pengadaan dan pengelolaan TI yaitu keamanan sistem dan pengelolaan sistem-nya.

5. Pengolahan data, dilakukan terhadap kuisioner yang dikumpulkan dengan menentukan skala rating dan memberikan skor terhadap setiap jawaban kuisioner yang diberikan kepada responden.

6. Analisa COBIT, pada tahap ini dilakukan analisis capability level yaitu melakukan pengukuran level dari setiap domain. Nilai Pengukuran didapat dari pengolahan data hasil kuisioner.

7. Analisa kondisi yang diharapkan, dilakukan dengan mengidentifikasi kondisi yang diharapkan intansi. Kondisi ini diharapkan mampu membantu intansi dalam mencapai tujuan mereka.

8. Tahapan kesimpulan, merupakan tahap terakhir. Kesimpulan memuat rangkuman keseluruhan dan hasil penelitian.

\subsection{Pengumpulan Data}

Adapun teknik pengumpulan data dalam penelitian ini, yaitu :

1. Kuisioner

Kuisioner merupakan teknik pengumpulan data yang dilakukan dengan cara memberi seperangkat pertanyaan atau pernyataan secara tertulis kepada responden untuk dijawabnya.[3] Kuisioner ini disusun berdasarkan pemahaman penulis mengenai COBIT terutama domain DSS01 dan DSS05.

2. Wawancara

Wawancara digunakan sebagai teknik pengumpulan data untuk menemukan permasalahan yang harus diteliti dan juga apabila peneliti ingin mengetahui hal-hal dari responden yang lebih mendalam.[4] Pada metode ini, penulis melakukan wawancara langsung terhadap responden agar memperoleh data yang relevan.

\subsection{Instrumen Penelitian}

1. Kuisioner 
Dalam penelitian ini peneliti menggunakan instrumen berupa kuisioner. Kuisioner ini tersaji dengan berupa pertanyaan-pertanyaan yang di susun dengan aktifias-aktifitas yang terdapat pada domain DSS01 dan DSS05 yang mempunyai nilai atau skala. [5]

2. Wawancara

Wawancara merupakan salah satu instrumen penelitian yang sering digunakan untuk melakukan penelitian kualitatif. Data yang diperoleh dari hasil wawancara berupa data-data mengenai prosedur sistem dan alur berjalannya sistem terutama mengenai keamanan TI dan pengelolaan operasi TI.[6]

3. Skala Pengukuran Ordinal

Pada penelitian ini penulis menggunakan teknik pengukuran ordinal dalam pembuatan kuisioner. Pengukuran ordinal merupakan pengukuran yang menyatakan kategori dan melakukan rangking pada kategori. Dengan ukuran nominal digunakan untuk mengurutkan objek dari terendah hinggga tertinggi. Pengurutan objek (nilai rangking) nomor $1=$ Sangat Tidak Setuju, 2 = Tidak Setuju, 3 = Ragu-ragu, 4 = Setuju, 5 = Sangat Setuju[7].

\subsection{Analisis Data}

Pada bagian ini data hasil kuisioner akan diperhitungan dengan menggunakan rumus indeks, nilai rangking didapat dengan cara melakukan proses perhitungan dalam bentuk tahapan dengan rumus indeks dibawa h ini[8] :

$$
\text { Indeks ke } 1=\frac{\text { Total semua nilai responden }}{\text { Jumlah Responden }}
$$

Setelah melakukan perhitungan indeks 1 selesai dengan hasil dari total nilai responden dibagi dengan jumlah responden, setelah itu dilakukan perhitungan rumus indeks kedua seperti berikut :

$$
\text { Indeks ke } 2=\frac{\text { Nilai indeks } 1}{\text { Jumlah Pertanyaan Kuesioner Untuk Setiap Domain }}
$$

Selanjutnya setelah melakukan perhitungan indeks 3 dari hasil perhitungan indeks 2 dengan Nilai indeks 1 dibagi dengan mengunakan jumlah pertanyaan kuesioner pada setiap domain, dari hasil tersebut dilakukan perhitungan dengan memakai rumus indeks ke 3 berikut :

$$
\text { Indeks ke } 3=\frac{\text { Nilai indeks } 2}{\text { Skala ratingnya ada } 5 \text { (1 sampai dengan } 5 \text { pilihan }) \times 100 \%}
$$

Setelah semua proses perhitungan dilakukan, dari hasil tersebut dilakukan pengukuran tingkat kematangan yang akan dijadikan sebagai acuan model maturity berdasarkan ISACA 2013 sebagai berikut :

Tabel 1. Tingkat Maturity Level (ISACA, 2013)

\begin{tabular}{cl}
\hline Index & \multicolumn{1}{c}{ Tingat Maturity Model } \\
\hline 0 & Incomplete Process (Proses Tidak Dilaksanakan atau gagal). \\
1 & Performed Process (Proses Diimplementasikan) \\
2 & Managed Process (Proses Dikelola) \\
3 & Established Process (Proses Dikomunikasikan) \\
4 & Predictable Process (Proses Dimonitor dan Diukur) \\
5 & Optimising Process (Proses Optimasi atau diprediksi) \\
\hline
\end{tabular}

Selanjutnya Ketika hasil dari perhitungan kuisioner telah melakukan proses penjumlahan dan menghasilkan nilai dalam bentuk bilangan bulat, maka dilakukan skala pembulatan sebagai berikut:

Tabel 2. Skala Pembulatan Indeks

\begin{tabular}{cc}
\hline SKALA PEMBULATAN & TINGKAT CAPITABILITY MODEL \\
\hline $4,51-5,0$ & 5 \\
$3,51-4,5$ & 4 \\
$2,51-3,5$ & 3 \\
$1,51-2,5$ & 2 \\
$0,51-1,5$ & 1 \\
$0-0,5$ & 0 \\
\hline
\end{tabular}

Tahap berikutnya adalah analisis GAP, setelah skala pembulatan indeks maka langkah selanjutnya adalah mencari nilai GAP dengan rumus perhitungan berikut :

$$
\text { GAP = Expected Level Capability - Level Capability }
$$

Expected level didapatkan dari kuisioner, dengan memprediksi level capability berdasarkan dari nilai jawaban kuisioner yang dipilih terbanyak. 


\subsection{Analisa COBIT 5}

Pada tahapan ini dilakukan pengukuran tingkat kapabilitas bagi setiap domain DSS. Pengukuran didapat dari pengolahan data kuisioner yang diajukan kepada pihak instans [9].

\subsection{COBIT 5}

COBIT 5 merupakan pengembangan dari COBIT 4.1 yang merupakan salah satu framework yang digunakan untuk melakukan proses audit. COBIT 5 adalah kerangka bisnis untuk tata kelola dan manajemen perusahaan IT (IT governance framework), dan juga kumpulan alat yang mendukung para manajer untuk menjembatani jarak (gap) antara kebutuhan yang dikendalikan (control requirements), masalah teknis (technical issues) dan resiko bisnis (business risk). COBIT dikembangkan oleh IT Governance Institute (ITGI) yang merupakan bagian dari Information Systems Audit and Control Association (ISACA)[10]. COBIT 5 memungkinkan teknologi informasi melakukan tata kelola dan manajemen secara holistik untuk keseluruhan enterprise, mengelola bisnis dari ujung ke ujung, bertanggung jawab pada keseluruhan area fungsi teknologi informasi. Selain itu juga dalam COBIT 5 menyediakan fasilitas dalam cakupan stakeholder internal dan eksternal. COBIT 5 bersikap global dan bermanfat untuk semua enterprise dengan berbagai skala, baik komersial, non profit, maupun sektor publik. COBIT 5 mempunyai lima prinsip (ISACA, 2012)[11].

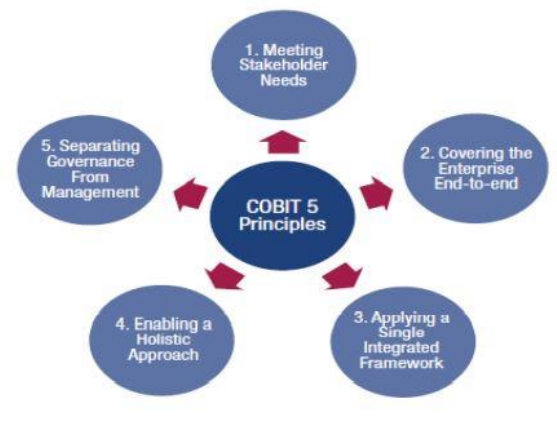

Gambar 2. Prinsip COBIT 5 (ISACA, 2012)

COBIT 5 berdasarkan lima prinsip kunci pada gambar 2.1 untuk tata kelola dan manajemen TI (ISACA, 2012) adalah :

1. Prinsip $1:$ Menemukan kebutuhan stakeholder

2. Prinsip 2 : Mencakup ujung ke ujung enterprise

3. Prinsip 3 : Mengaplikasikan yang tunggal, mengintegrasikan framework

4. Prinsip 4 : Mengaktifkan pendekatan holistik

5. Prinsip 5 : Memisahkan tata kelola dengan manajemen

\subsection{Domain DSS}

Domain DSS berkaitan dengan pengiriman aktual dan dukungan layanan yang dibutuhkan, yang meliputi pelayanan, pengelolaan keamanan dan kelangsungan, dukungan layanan bagi pengguna, dan manajemen data dan fasilitas operasional. Dalam Domain DSS terdapat 6 sub domain yaitu :

1. DSS01 Mengelola operasi.

2. DSS02 Mengelola permintaan layanan dan insiden.

3. DSS03 Mengelola masalah.

4. DSS04 Mengelola kontinuitas.

5. DSS05 Mengelola layanan keamanan.

6. DSS06 Mengelola kontrol proses bisnis[12].

\section{HASIL DAN PEMBAHASAN}

Berdasarkan hasil survei wawancara dan pengisian kuisioner yang telah dilakukan pihak instansi maka langkah selanjutnya mengolah data-data hasil kuisioner tersebut ke dalam perhitungan tingkat kapabilitas agar diperoleh tingkatan yang sesuai dengan standar COBIT5, adapun langkah-langkah perhitungan tersebut terdapat pada penjelasan dibawah ini:

\subsection{Perhitungan Tingkat Kapabilitas Domain DSS01}

Dari hasil perhitungan diperoleh nilai capability level sub domain DSS01 (Mengelola Operasi Sistem) pada tabel berikut:

Tabel 3. Rekapitulasi Capability Level DSS01

\begin{tabular}{ccc}
\hline No & Sub Domain & Capability Level (Indeks 1) \\
\hline 1 & DSS01.01 & 3,41 \\
\hline
\end{tabular}




\begin{tabular}{ccc}
\hline No & Sub Domain & Capability Level (Indeks 1) \\
\hline 2 & DSS01.02 & 3,83 \\
3 & DSS01.03 & 3,91 \\
4 & DSS01.04 & 3,41 \\
5 & DSS01.05 & 3,75 \\
6 & DSS01.06 & 3,75 \\
7 & DSS01.07 & 3,83 \\
8 & DSS01.08 & 3,91 \\
9 & DSS01.09 & 4 \\
10 & DSS01.10 & 3,66 \\
\hline \multicolumn{3}{r}{ Jumlah Indeks 1 } \\
\multicolumn{2}{c}{ Indeks 2 (Current Capability) } & 37,46 \\
& Indeks 3 (Level Capability 100\%) & 75 \\
\hline
\end{tabular}

Pada tabel diatas menjelaskan subdomain DSS01 yang dimana terdapat beberapa subdomain lagi untuk DSS01 yaitu DSS01.01 sampai dengan DSS01.10 yang diketahui berdasarkan jumlah pernyataan kuisioner, kemudian hasil capability level didapat berdasarkan jumlah skala penilaian dibagi dengan rules kuisioner yaitu 12 untuk DSS01. Untuk perhitungan indeks 1 , indeks 2 , dan indeks 3 disesuaikan dengan rumus yang ada pada bagian analisis data.

\subsection{Perhitungan Tingkat Kapabilitas Domain DSS05}

Dari hasil perhitungan diperoleh nilai capability level sub domain DSS05 (Mengelola Keamanan Sistem) pada tabel berikut :

Tabel 4. Rekapitulasi Capability level DSS05

\begin{tabular}{ccc}
\hline No & Sub Domain & Capability Level (Indeks 1) \\
\hline 1 & DSS05.01 & 3,9 \\
2 & DSS05.02 & 4,1 \\
3 & DSS05.03 & 4,2 \\
4 & DSS05.04 & 4,3 \\
5 & DSS05.05 & 4,2 \\
6 & DSS05.06 & 3,9 \\
7 & DSS05.07 & 4,2 \\
8 & DSS05.08 & 4,7 \\
9 & DSS05.09 & 4 \\
10 & DSS05.10 & 4,2 \\
\hline & Jumlah Indeks 1 & 41,7 \\
& Indeks 2 (Current Capability) & 4,17 \\
& Indeks 3 (Level Capability 100\%) & 83,4 \\
\hline
\end{tabular}

Pada tabel di atas menjelaskan subdomain DSS05 yang dimana terdapat beberapa subdomain lagi untuk DSS05 yaitu DSS05.01 sampai dengan DSS05.10 yang diketahui berdasarkan jumlah pernyataan kuisioner, kemudian hasil capability level didapat berdasarkan jumlah skala penilaian dibagi dengan rules kuisioner yaitu 10 untuk DSS05. Untuk perhitungan indeks 1 , indeks 2 , dan indeks 3 disesuaikan dengan rumus yang ada pada bagian analisis data.

\subsection{Kapabilitas Level}

Berikut adalah capability level domain DSS01 dan DSS05 yang mana diperoleh berdasarkan hasil perhitungan pada Tabel 3 dan Tabel 4, terdapat dua bagian yaitu current capability dan dalam bentuk persentase.

Tabel 5. Capability Level

\begin{tabular}{ccc}
\hline Domain & Current Capability & Persentase $(\%)$ \\
\hline DSS01 & 3,75 & 75 \\
DSS05 & 4,17 & 83,4 \\
\hline
\end{tabular}

Pada tabel diatas mendeskripsikan tingkat kapabilitas atau capability level, yang dimana DSS01 memiliki tingkat kapabilitas 3,75 dengan persentase 75, sedangkan untuk DSS05 memiliki tingkat kapabilitas 4,17 dengan persentase 83,4 . Yang dimana current capability dan persentasi didapat berdasarkan indeks 2 dan persentase berdasarkan indeks 3.

\subsection{Pembulatan Indeks Dan Analisis GAP}

Berikut adalah Analisa GAP dan Pembulatan indeks berdasarkan skala pembulatan indeks (ISACA, 2013). 
Tabel 6. Pembulatan Skala Indeks Dan Analisis GAP

\begin{tabular}{ccc|c|c}
\hline Domain & Current Capability & Capability Level & Expected Level & GAP \\
\hline DSS01 & 3,75 & 4 & 5 & 1 \\
DSS05 & 4,17 & 4 & 5 & 1 \\
\hline
\end{tabular}

Pada tabel diatas diperoleh hasil capability level DSS01 (Mengelola operasi) berada di level 4 Predictable Process (Proses Dimonitor dan Diukur) dan DSS05 (Mengelola keamanan layanan) juga berada pada level 4 Predictable Process.

\section{KESIMPULAN}

Berdasarkan pembahasan dan hasil perhitungan mengenai COBIT5 untuk mengukur tingkat kualitas tata kelola sistem pada pengoperasian sistem dan pengelolaan keamanan sistem di KSPPS BMT UNIT-068 SAMPIT, melalui pengolahan hasil kuisioner dari responden dapat disimpulkan bahwa Tingkat kapabilitas pada Domain DSS01 (Mengelola operasi sistem) berada pada level 4 (Predictable process) dengan skor 3,75. Sedangkan Tingkat kapabilitas pada Domain DSS05 (Mengelola keamanan layanan) berada pada level 4 (Predictable process) dengan skor 4,17.

\section{REFERENCES}

[1] M. Ridwan, "Muhammad Ridwan, Manajemen Baitul Maal wa Tamwil , Yogyakarta: Pinbuk D.I.Y, 2004, hal. 126. 1 1,” pp. 126.

[2] S. Ahmad and R. Harahap, "Peran Baitul Mal Wa Tamwil (Bmt) Dalam Pengembangan Ekonomi Umat," Hum. Falah, vol. 7, no. 1, pp. 19-29, 2020.

[3] A. W. Doni, "Evaluasi SDM Sistem Informasi Akademik Poltekkes Kemenkes Padang Menggunakan Framework COBIT 5," $J$. RESTI (Rekayasa Sist. dan Teknol. Informasi), vol. 1, no. 2, pp. 146-152, 2017, doi: 10.29207/resti.v1i2.62.

[4] J. Sari, R. Forijati, and D. Z. Arifin, "PENJUALAN PADA HOME INDUSTRI BAKPOW KIMYEN Oleh : Dibimbing oleh : SURAT PERNYATAAN ARTIKEL SKRIPSI TAHUN 2019,” 2019.

[5] A. Pratomo, "analisa pengaruh partisipasi dan kepuasan pemakai terhadap kinerja dalam pengembangan sistem informasi berbasis web di P3M Poliban," J. positif, vol. 3, pp. 63-73, 2017.

[6] D. Prasanti, "Penggunaan Media Komunikasi Bagi Remaja Perempuan Dalam Pencarian Informasi Kesehatan," LONTAR J. Ilmu Komun., vol. 6, no. 1, pp. 13-21, 2018, doi: 10.30656/lontar.v6i1.645.

[7] Hardyansyah, "Pengaruh kompetensi sumber daya manusia terhadap kualitas laporan keuangan," Skripsi, p. 63, 2010.

[8] T. S. Agoan, H. F. Wowor, and S. Karouw, "Analisa Tingkat Kematangan Teknologi Informasi Pada Dinas Komunikasi Dan Informatika Kota Manado Menggunakan Framework COBIT 5 Domain Evaluate, Deirect, Monitor (EDM) dan Deliver, Service, and Support (DSS)," J. Tek. Inform., vol. 10, no. 1, pp. 1-9, 2017, doi: 10.35793/jti.10.1.2017.15627.

[9] E. Ekowansyah, Y. H. Chrisnanto, Puspita, and N. Sabrina, "Audit Sistem Informasi Akademik Menggunakan COBIT 5 di Universitas Jenderal Achmad Yani," Pros. Semin. Nas. Komput. dan Inform. 2017 (ISBN 978 - 602 - 60250 - 1 -2), vol. 2017, pp. 201-206, 2017, [Online]. Available: http://www.senaski.unikom.ac.id/prosiding-file/201-206 erdis ekowansyah dkk 6 hal.pdf.

[10] A. Nuratmojo, E. Darwiyanto, S. T. Mt, G. Agung, A. Wisudiawan, and S. Kom, "Penerapan COBIT 5 Domain DSS ( Deliver , Service, Support ) untuk Audit Infrastruktur Teknologi Informasi FMS PT Grand Indonesia Application COBIT 5 DSS ( Deliver , Service , and Support ) Domain for Information Technology Infrastructure Audit FMS PT Gra,” vol. 2, no. 2, pp. 6499-6506, 2015.

[11] F. S. Sulaeman, “Audit Sistem Informasi Framework Cobit 5 Data Nasabah PT . AF per tahun,” vol. 7, no. 2, pp. 37-42, 2015.

[12] D. Firmansyah, "Pengukuran Kapabilitas Pengelolaan Sistem Informasi Sub Domain Deliver , Service , Support 01 Menggunakan Framework Cobit 5 Studi Kasus : Politeknik Komputer Niaga LPKIA Bandung,” pp. 9-10, 2015. 